\title{
Morphology and ecological zonation of Caribbean reef corals: the Montastraea 'annularis' species complex
}

\author{
John M. Pandolfi ${ }^{1, *}$, Ann F. Budd ${ }^{2}$ \\ ${ }^{1}$ Centre for Marine Studies and School of Earth Sciences, ARC Centre of Excellence in Coral Reef Studies, \\ The University of Queensland, Brisbane, Queensland 4072, Australia \\ ${ }^{2}$ Department of Geoscience, University of Iowa, Iowa City, Iowa 52242, USA
}

\begin{abstract}
Estimates of species diversity on coral reefs are extremely high, yet hidden biological diversity makes even these, underestimates. The morphological complexity in the Caribbean reef coral Montastraea 'annularis' was originally interpreted as a single species because colony growth form was highly correlated with depth distribution from the coral reefs surrounding Carrie Bow Cay in Belize. This 'species' has since been re-interpreted from other Caribbean reefs as representing at least 3 separate species based on morphometric, genetic, reproductive, and ecological differences. We revisited the shallow water coral reefs in the Carrie Bow Cay region to test whether the 3 species could be recognized, and if so, what their ecological distribution might be. We have found that the 3 recently described species of the Montastraea 'annularis' species complex can be readily identified using both colony forms observed in the field and morphometric analyses of the corallite wall, and that their abundance distributions vary significantly along depth gradients. Morphometric comparison with both colonies from Panamá and results from transplantation experiments in Jamaica show consistent patterns in the morphological characters that differentiate species and growth forms and are useful in understanding the geographic, environmental, and genetic components of variability within the species complex. All 3 species have a broad depth distribution, but each species dominates in a preferred depth zone, suggesting a high degree of niche differentiation. Our results confirm the existence of hidden biological diversity in Caribbean reef corals and call for caution in future estimates of biological diversity on coral reefs.
\end{abstract}

KEY WORDS: Corals · Caribbean Sea $\cdot$ Coral reef ecology $\cdot$ Zonation · Ecotones $\cdot$ Morphometrics · Community assembly $\cdot$ Community structure $\cdot$ Evolution

\section{INTRODUCTION}

Interpretation of community structure and estimation of biodiversity through space and time rely heavily upon good systematics. Reef corals display a high degree of phenotypic plasticity, which may confuse attempts to unravel patterns of community structure and biodiversity. In Caribbean reef corals, at least 3 members of the Montastraea 'annularis' species complex have been detected where 1 species was thought to have existed. Montastraea 'annularis' (sensu lato) was thought to have occupied all depths on coral reefs, only changing its form to conform to changes in light penetration and wave energy (Graus \& Macintyre 1976, 1982).

Montastraea 'annularis' has long held the interest of coral reef ecologists because it is one of the most dominant corals of Caribbean reefs (Goreau 1959). For decades, this coral was considered the archetypal generalist (Connell 1978) with both a seemingly limitless ability for phenotypic plasticity in growth form, and a distribution ranging from the intertidal to over $80 \mathrm{~m}$ 
water depth (Goreau \& Wells 1967). The extensive variability in colony morphology (columns, massive heads, and sheets/plates) exhibited over this range was believed to be an environmental response to differing light levels (Graus \& Macintyre 1976, 1982). More recently, a number of features have been found to co-vary with the different types of colony morphologies, including allozymes, reproductive biology, aggressive behavior, ecology, growth rate, corallite structure, and stable isotopes (Knowlton et al. 1992, 1997, Van Veghel \& Bak 1993, 1994, Van Veghel et al. 1996, Lopez \& Knowlton 1997, Lopez et al. 1999, Manica \& Carter 2000, Knowlton \& Budd 2001, Pandolfi et al. 2002, Budd \& Pandolfi 2004, Fukami et al. 2004, Holcomb et al. 2004, Levitan et al. 2004).

On the basis of these characteristics, modern Montastraea 'annularis' (sensu lato), long thought to represent 1 species, is now thought to consist of a complex of at least 3 sympatric species in shallow- to mid-reef depths in Central America that differ in overall colony shape and the shape of the growing edge (Weil \& Knowlton 1994). M. annularis s.s. Ellis \& Solander, 1786 generally forms columns, M. faveolata Ellis \& Solander, 1786 generally forms smooth, skirted, massive mounds, and M. franksi Gregory, 1895 forms bumpy, irregular mounds and plates. Morphometric analyses of non-traditional skeletal characters including septal relief and corallite structure show that the species are morphologically distinct (Budd \& Johnson 1996, Budd \& Klaus 2001, Knowlton \& Budd 2001), and recent data showed that growth rates in Pleistocene lineages are also highly divergent (Pandolfi et al. 2002).

The purpose of the present paper is to re-visit the sites where over $30 \mathrm{yr}$ ago Montastraea 'annularis' was considered a single species with large morphological variability (Graus \& Macintyre 1976, 1982). Early excellent work on the species group used mathematical models to study colony growth. However, advances in molecular techniques, using new tools over the past decade or so that were not available to Graus \& Macintyre $(1976,1982)$, can now distinguish closely related species within the group (Knowlton et al. 1992, Weil \& Knowlton 1994, Lopez et al. 1999, Fukami et al. 2004, Willis et al. 2006, Klaus et al. 2007). Now we can illuminate the ecological distribution of the newly discovered species in this important area of the Caribbean Sea. In this paper, we show that members of the species com- plex are distributed non-randomly along environmental resource gradients (i.e. light), an indication that niche differentiation is at least in part controlling species distribution patterns.

We also examined the morphological variation within the Montastraea 'annularis' species complex across growth forms, species, and Caribbean sites. Separate species can be differentiated morphologically in Belize, the area where they were originally thought to represent phenotypic plasticity of a single species. We then compared the morphological variability of Belize specimens with those previously described from Panamá and Jamaica, which helps to determine the degree to which various morphological traits display phenotypic plasticity along environmental gradients.

\section{MATERIALS AND METHODS}

Morphometric analysis. Sampling: In order to examine morphological variation within the Montastraea 'annularis' complex, we sampled from 1 to $30 \mathrm{~m}$ water depth from the lagoonal and windward sides of Carrie Bow Cay reef (Fig. 1) (see Table A1, available in MEPS Supplementary Material at: www.int-res.com/articles/ suppl/m369p089_app.pdf). Between 4 and 14 colonies were sampled from each of 5 depth intervals along the windward reef front $(5,10,15,20$, and $30 \mathrm{~m})$, and 14

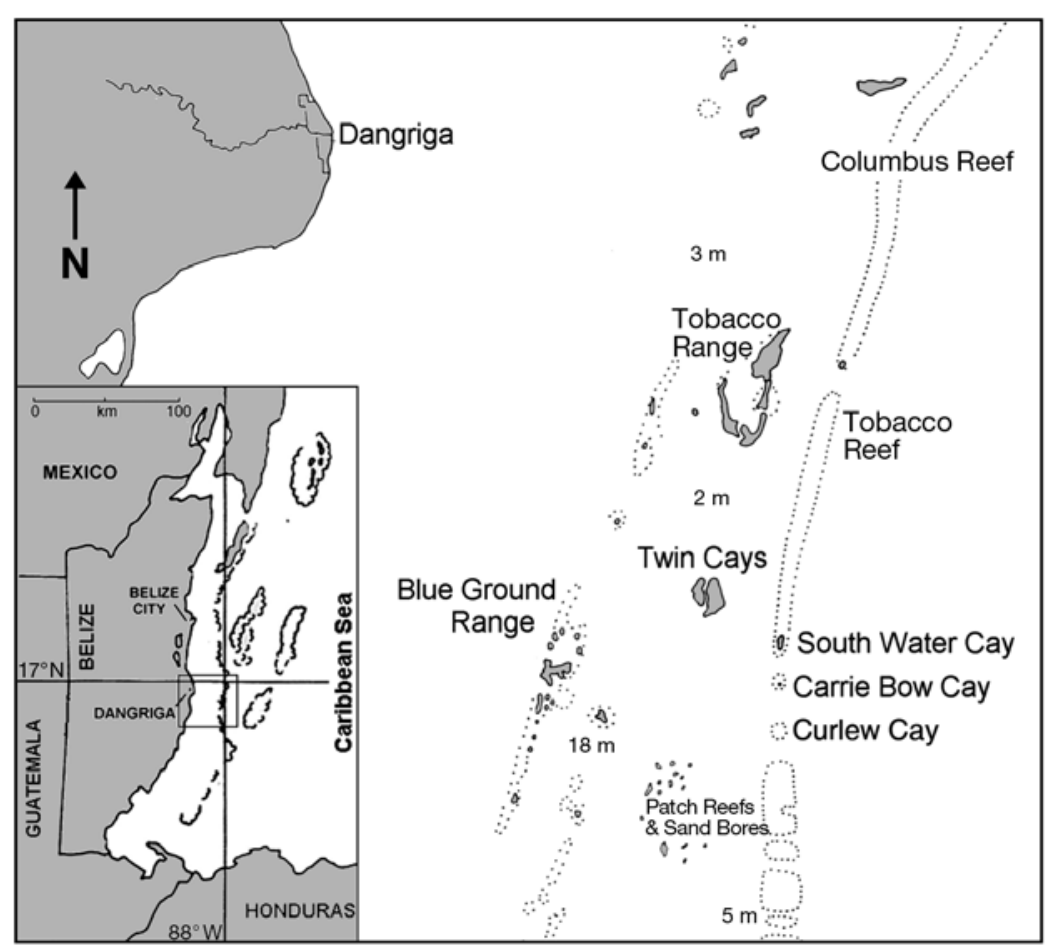

Fig. 1. The 3 study sites from Belize: Carrie Bow Cay, Tobacco Reef (due east of South Water Cay), and Curlew Cay 
colonies were sampled from $2 \mathrm{~m}$ water depth within the back reef lagoon at Carrie Bow Cay, for a total of 50 samples (see Fig. A1, available in MEPS Supplementary Material at: www.int-res.com/articles/suppl/ m369p089_app.pdf). Following the approach of Knowlton et al. (1992), Weil \& Knowlton (1994), and Pandolfi et al. (2002), the samples were initially identified in the field using growth form (column, massive, plate). Colonies composed of multiple skeletal columns (higher than wide) with diameters usually 10 to $35 \mathrm{~cm}$ thick were tentatively identified as $M$. annularis s.s.; colonies composed of a usually single mound-shaped skeletal mass with a diameter $>35 \mathrm{~cm}$ thick were tentatively identified as $M$. faveolata; and colonies composed of elongate, thin plates ( $<25 \mathrm{~cm}$ high) were tentatively identified as $M$. franksi. Our samples from Belize were collected from a greater range of environments, including exposed reef fronts, than those previously studied from Panamá, which came from more protected habitats (Knowlton et al. 1997, Fukami et al. 2004). Further refinement of species was made in the laboratory through inspection of videos taken in the field and inspection of colony skeletons under a stereomicroscope, taking into account corallite characteristics (size, distribution) and relief on calical surfaces (see Budd \& Klaus 2001, Knowlton \& Budd 2001). See Table A1 for field and laboratory identifications of sampled colonies.

Data collection: Morphometric data were collected on transverse thin sections of 61 colonies, including the 50 colonies described above ('Sampling') and 11 additional colonies sampled by I. Macintyre around Carrie Bow Cay (Table A1). We digitized the Cartesian coordinates $(x-y)$ for 19 landmarks on 6 corallites in transverse thin sections from the top of each colony (Fig. 2) (see Table A2, available in MEPS Supplementary Material at: www.int-res.com/articles/suppl/ m369p089_app.pdf). Our approach was similar to those applied earlier in studies of the species complex in the late Pleistocene of the Bahamas (Budd \& Pandolfi 2004) and Barbados (Pandolfi et al. 2002), the PlioPleistocene of Costa Rica and Panamá (Budd \& Klaus 2001), and the late Miocene and late Pleistocene of the Dominican Republic (Klaus \& Budd 2003).

Size and shape coordinates (Bookstein 1991, Zelditch et al. 2004) were calculated for the landmark data using the computer program CoordGen6 in the IMP software series (Integrated Morphometrics Package, 2004, written by H. David Sheets, available at http://www2.canisius.edu/ $\sim$ sheets/morphsoft.html). Centroid size was calculated by summing the squared distances from each of the 19 landmarks to a common centroid. Shape coordinates were calculated for triplets of points in which Points 11 and 12 (Table 1) were fixed as the baseline. To facilitate morphological interpretation, 23 shape coordinates associated with the structure and development of the corallite wall and costosepta (Table 1) were selected for use in statistical analyses.

Variation among Belize growth forms (Analysis 1): To test whether the 3 Belize growth forms represented distinct species, we performed canonical discriminant analyses (SPSS 14.0) using colony means of the 24 variables (23 shape coordinates and centroid size) and the 3 growth forms as groups. Cross validation was performed by treating $n-1$ out of $n$ observations as the dataset to determine the discrimination rule and using the rule to classify the 1 observation left out. Nonpara-
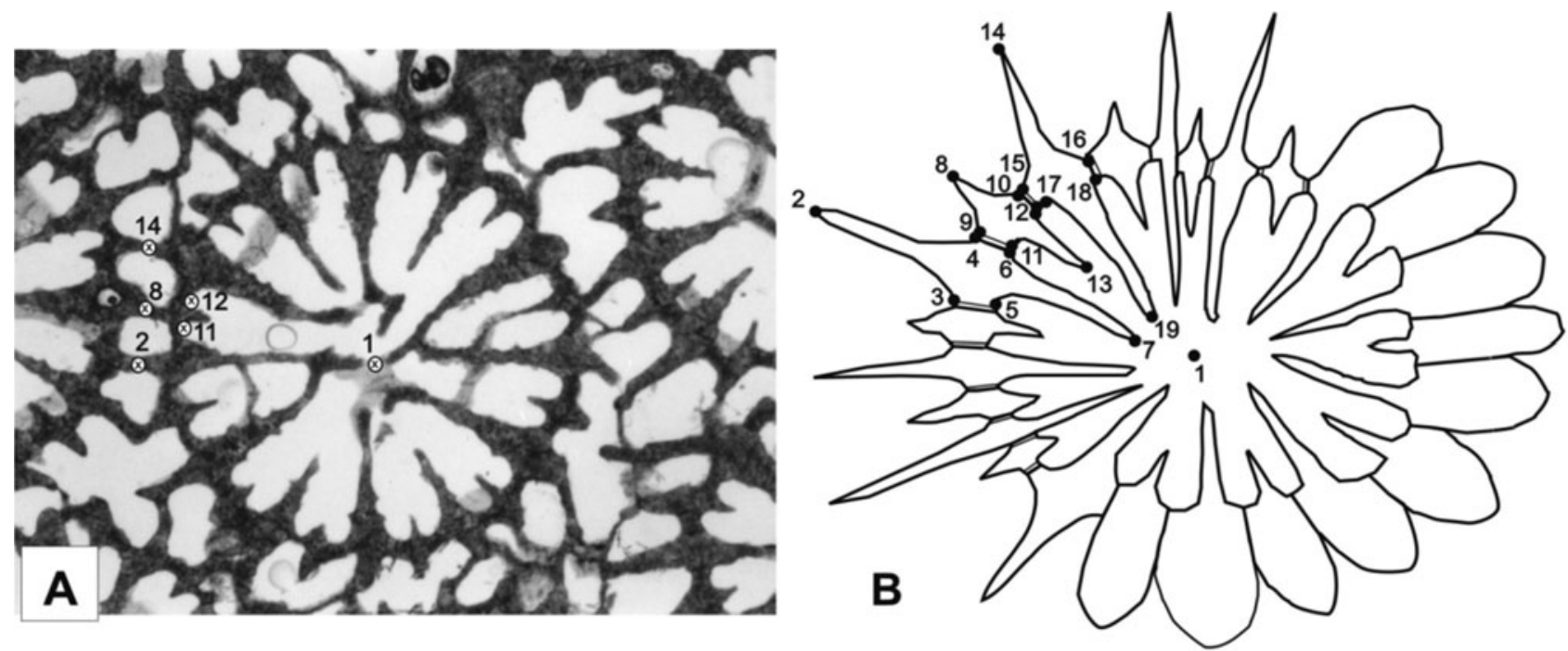

Fig. 2. Two-dimensional Cartesian coordinates collected for 19 landmarks on transverse thin sections of corallites. Point numbers 11 and 12 were used as the baseline when calculating Bookstein shape coordinates. The landmarks characterize the structure of the corallite wall and costal extensions beyond the wall. (A) Selected landmarks on a photograph of a corallite. (B) All 19 landmarks on a schematic drawing of a corallite 


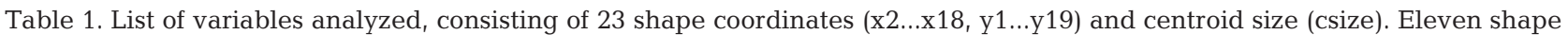
coordinates that were constrained due to radial symmetry $(x 1, x 7, x 8, x 13, x 19, y 6, y 17)$ or that crossed several morphological features (x3, y5, x16, y18) were not included. Numbers for Tukey's HSD test refer to Belize growth forms $(4=$ columns, $5=$ massives, $6=$ plates $)$ and Panamanian members of the Montastraea 'annularis' complex $(1=$ M. annularis s.s., $2=M$. faveolata, $3=$ M. franksi). Species may belong to 2 groups (homogeneous subsets), if there is overlap among groups. Groups are in square brackets. ns = not significant

\begin{tabular}{|c|c|c|}
\hline $\begin{array}{l}\text { Variables (shape } \\
\text { coordinates) }\end{array}$ & $\begin{array}{l}\text { Related morphological } \\
\text { feature }\end{array}$ & $\begin{array}{l}\text { Tukey's HSD multiple comparisons test } \\
\text { (homogeneous subsets [in brackets] for } \mathrm{p}<0.05 \text { ) }\end{array}$ \\
\hline $\mathrm{x} 14, \mathrm{y} 14$ & Extension of primary costa & {$[3=1=2=4=5]<[1=2=4=5=6] ; \mathrm{ns}$} \\
\hline $\mathrm{x} 2, \mathrm{y} 2$ & Extension of secondary costa & $\begin{array}{l}{[2=3=5=4=1]<[3=5=4=1=6]} \\
{[6=3=4=1]<[3=4=1=5]<[4=1=5=2]}\end{array}$ \\
\hline y8 & Extension of tertiary costa & {$[6=3=4]<[3=4=1]<[4=1=5]<[1=5=2]$} \\
\hline y19 & Length of primary septum & {$[3=4=6=1]<[6=1=5]<[1=5=2]$} \\
\hline y7 & Length of secondary septum & {$[3=6=1=4]<[4=5]<[5=2]$} \\
\hline y13 & Length of tertiary septum & ns \\
\hline $\mathrm{y} 4, \mathrm{y} 15$ & Wall thickness & $\begin{array}{l}{[6=3]<[3=4]<[1=5=2]} \\
{[6=3]<[3=4]<[5=1=2]}\end{array}$ \\
\hline y9, y10 & Wall thickness & {$[6=3]<[3=4]<[1=5=2] ;[6=3]<[3=4]<[1=5=2]$} \\
\hline $\mathrm{x} 4, \mathrm{x} 15$ & $\begin{array}{l}\text { Outer length of wall dissepiment } \\
\text { and tertiary costoseptum thickness }\end{array}$ & $\begin{array}{l}{[3=2=5=4=6]<[5=4=6=1]} \\
{[3=1=2=4=5]<[2=4=5=6]}\end{array}$ \\
\hline$x 6, x 17$ & Inner length of wall dissepiment & {$[2=5]<[5=1]<[1=4=6=3] ;[3=6=1=4]<[5=2]$} \\
\hline y16 & $\begin{array}{l}\text { Outer diagonal across primary } \\
\text { costoseptum (plus dissepiment) }\end{array}$ & {$[6=3=4]<[5=1=2]$} \\
\hline $\mathrm{x} 18$ & $\begin{array}{l}\text { Inner thickness of primary } \\
\text { costoseptum (plus dissepiment) }\end{array}$ & {$[6=3=4=1]<[4=1=5=2]$} \\
\hline y3 & $\begin{array}{l}\text { Outer diagonal across secondary } \\
\text { costoseptum (plus dissepiment) }\end{array}$ & {$[6=3]<[3=4]<[5=1=2]$} \\
\hline $\mathrm{x} 5$ & $\begin{array}{l}\text { Inner thickness of secondary } \\
\text { costoseptum (plus dissepiment) }\end{array}$ & {$[5=2=4=1=6]<[4=1=6=3]$} \\
\hline $\mathrm{x} 9, \mathrm{x} 10$ & Outer thickness of tertiary costoseptum & $3<[6=4=2=5=1] ;[2=3=1=5]<[3=1=5=4]<[4=6]$ \\
\hline y1 & Corallite diameter & {$[3=6=4=1]<[4=1=2]<[1=2=5]$} \\
\hline csize & Centroid size (all 19 landmarks) & {$[1=2=5=4]<[6=3]$} \\
\hline
\end{tabular}

metric statistical tests (Mann-Whitney $U$, Kruskal-Wallis) were also used to test for differences in canonical variate scores among groups.

Comparison with species in Panamá (Analysis 2): To test whether the 3 Belize growth forms were the same as the members of the Montastraea 'annularis' complex in Panamá, we compared them with data collected in the same manner on transverse thin sections of 30 genetically characterized modern colonies, consisting of $10 \mathrm{M}$. annularis s.s. (columns), $10 \mathrm{M}$. faveolata (massives), and $10 \mathrm{M}$. franksi (plates) from a shallow protected fringing reef environment $(\sim 10 \mathrm{~m}$ in water depth) in the San Blas Islands of Panamá. This modern dataset is described in detail in Budd \& Klaus (2001) and Fukami et al. (2004). In addition to multivariate analyses, we performed univariate comparisons of means by comparing the 3 Belize species with the Panamá species using multiple comparisons tests, namely Tukey's honestly significant difference (HSD) test. Tukey's HSD uses the Studentized range statistic to make all pairwise comparisons between groups.

Environmental variation within growth forms (Analyses 3 to 5): To examine patterns of variation within each of the 3 growth forms (Analysis $3=$ columns; Analysis $4=$ massives; Analysis 5 = plates), we performed canonical discriminant analysis separately on each Belize growth form using the same 24 morphometric variables and 4 environmental groups: (1) $<5 \mathrm{~m}$, (2) 5 to $12 \mathrm{~m}$, (3) 13 to $30 \mathrm{~m}$, and (4) >30 m.

Comparison of environmental variation within species with species differences (Analyses 6 and 7): To further compare patterns of variation within and between species, we also performed canonical discriminant analysis using the same 24 variables and the 3 species in Panamá and 3 populations of Montastraea faveolata from Discovery Bay, Jamaica, as groups (Analysis 6). We used specimens of the 3 species in Panamá in these analyses, because previous molecular work based on the same specimens (Fukami et al. 2004) has shown that the 3 species differ from one another genetically. Moreover, given that these specimens were all collected in the same reef environment, environmental variation is minimized. The Jamaican populations consisted of colonies that were reciprocally transplanted in 1974 among the following 3 reef environments: (1) 2 stations on the forereef at $20 \mathrm{~m}$ 
depth, (2) 1 station in the backreef lagoon at $15 \mathrm{~m}$ depth, and (3) 1 station on a patch reef at $5 \mathrm{~m}$ depth (Foster 1979, Budd 1993). In these experiments, 3 colonies were stained with alizarin and transplanted from each station to every other station, and 3 colonies were left at their original station as controls. The colonies were collected after 1 yr of growth, and transverse thin sections were prepared above and below the alizarin line within each colony. Canonical discriminant analyses were performed by comparing the 3 Panamá species with samples of the 3 Jamaican populations taken below the alizarin line (i.e. skeleton deposited before transplantation). To further test whether the variation observed between the 3 Jamaican populations could be attributed only to ecophenotypic plasticity, we performed additional analyses (Analysis 7) involving only the Jamaican populations, and compared samples taken below the alizarin line with samples taken above the alizarin line (i.e. skeleton deposited after transplantation).

Ecological analysis. Sampling: A hierarchical sampling design was used to compare and contrast species abundances and distribution from 3 sites and 5 depths, with 5 replicates per site and depth. Populations were sampled from the windward side of Carrie Bow Cay, Tobacco Reef to the north, and Curlew Cay to the south (Fig. 1). At all 3 sites, species abundances were derived along $20 \mathrm{~m}$ belt transects, oriented perpendicular to the depth gradient, from 5, 10, 15, 20, and 30 m water depth. The length along the transect of all colonies of the 3 species of the Montastraea 'annularis' species complex falling within $50 \mathrm{~cm}$ of the transect tape was recorded. At Carrie Bow Cay and Curlew Cay, we also sampled shallow water assemblages (2 $\mathrm{m}$ depth) from the lagoon.

Data analysis: Comparison of taxonomic composition among all possible pairs of transects (among depths and sites) was calculated using the Bray-Curtis dissimilarity coefficient (Bray \& Curtis 1957). Dissimilarity values range from 0 (for a pair of samples with identical taxonomic composition) to 1 (for a pair of samples with no taxa in common). Abundance data were transformed to their 4 th roots prior to the calculation to reduce the influence of occasional large abundance values for some taxa (Field et al. 1982).

Nonmetric multidimensional scaling (NMDS; Kruskal 1964) was used to provide a visual summary of the pattern of Bray-Curtis values among the 85 transects. This ordination technique has been shown to be one of the most effective methods available for the ordination of taxonomic composition data (Minchin 1987, Shi 1993). This method was chosen over other ordination techniques because it makes no assumptions about the underlying distribution of the data. The NMDS was run with 25 random starting configurations. Sample points closest together on the resulting 2-dimensional scatter plot represent transects with the most similar coral abundances.

To determine whether communities from different sites and depths had significantly different composition in their relative abundance of Montastraea 'annularis' species, we used analysis of similarities (ANOSIM; Clarke 1993, Clarke \& Warwick 2001) for the unbalanced design for all sites and depths, and permutational multivariate analysis of variance (PERMANOVA; Anderson 2001) for the balanced part of the data (all sites, but $2 \mathrm{~m}$ depth excluded, as there was no comparable 2 m lagoon setting for Tobacco Reef as exists on Curlew and Carrie Bow cays). In both analyses, both factors, site and depth were crossed, and for PERMANOVA, both factors were fixed. In both analyses, data were transformed to the 4 th root, and analyzed based on a Bray-Curtis dissimilarity matrix, using 10000 permutations. The ANOSIM and PERMANOVA tests allow unambiguous interpretation of the NMDS plots. Details of these methods can be found in Pandolfi \& Minchin (1995), Pandolfi (1996, 2001), Jackson et al. (1996) and Pandolfi \& Jackson (2001). ANOSIM and NMDS were performed using the PRIMER software package and PERMANOVA using the PERMANOVA program (Anderson 2005). Statistical significance was assessed at a probability level ( $\alpha$ ) of 0.05. Multiple comparisons were evaluated using the Bonferroni correction $(\alpha /$ no. of pairwise tests, where $\alpha=0.05)$.

\section{RESULTS}

\section{Species distinctiveness}

\section{Variation among Belize growth forms (Analysis 1)}

The results of the canonical discriminant analyses (Fig. 3) showed that the 3 Belize growth forms had statistically significant differences in corallite morphology and that no overlap occurred among groups (Fig. 3A). Classification results indicated that $98.4 \%$ of the originally grouped cases were correctly classified, and that $73.8 \%$ of the cross-validated grouped cases were correctly classified. Nonparametric statistical tests (Kruskal-Wallis, Mann-Whitney $U$ ) indicated that all 3 growth forms differed from one another on the first canonical variate ( $\mathrm{p} \ll 0.001)$, and that the columns differed from the other 2 growth forms on the second variate ( $p \ll 0.001$ for columns vs. massives, and for columns vs. plates; $\mathrm{p}=0.678$ for massives vs. plates). As indicated by the correlation table between individual variables and canonical variates (see Table A3, Analysis 1, available in MEPS Supplementary Material at: www.int-res.com/articles/suppl/m369p089_app.pdf), 

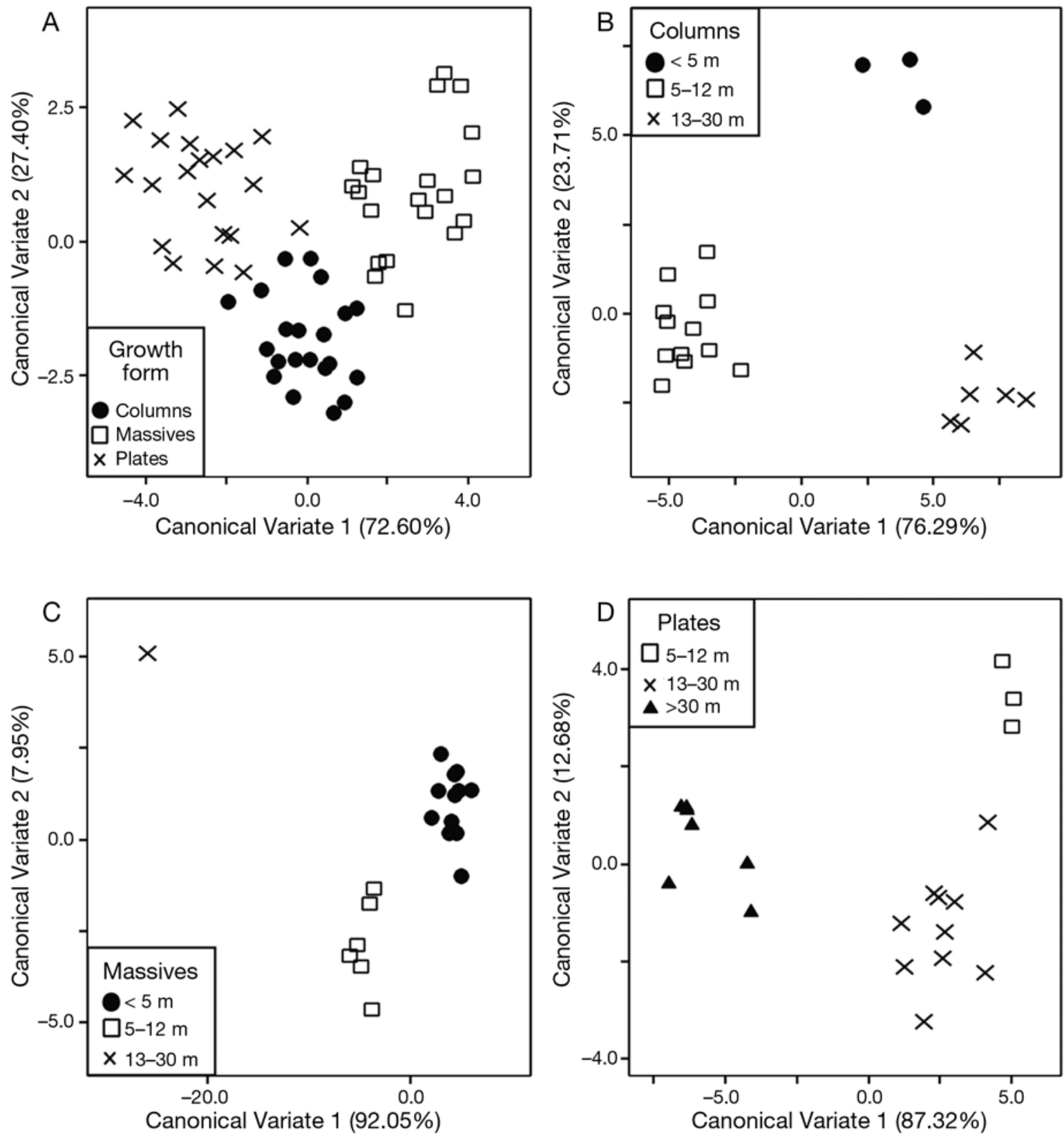

Fig. 3. Plots of scores on canonical variates comparing the 3 growth forms in Belize and colonies from different reef environments within each Belize growth form. Each point on the plots represents 1 colony. Correlations of canonical variates with individual variables are given in Table A3, available in MEPS Supplementary Material at www.int-res.com/articles/suppl/m369p089_app.pdf. (A) Analysis 1, comparing growth forms. (B) Analysis 3, comparing environments within columns. (C) Analysis 4, comparing environments within massives. (D) Analysis 5, comparing environments within plates

wall thickness (y4, y15, y9, y10, y3, y16) was strongly correlated with the first canonical variate. Corallite size (csize, y1, y19, y7) and dissepiment length (x6, $\mathrm{x} 17)$ had relatively high correlations with the second canonical variate. These results agreed with the results on multiple comparisons tests performed using the original variables (Table 1), which revealed that wall thickness ( $y 4, y 15, y 9, y 10)$ was thin in massive colonies, intermediate in columns, and thick in plates. Massives had larger corallite diameters (y1) and centroid sizes (csize), longer primary and secondary septa (y19, y7), and more extensive inner wall dissepiments $(\mathrm{x} 6, \mathrm{x} 17)$. The 3 growth forms did not differ in extension of costae (x14, y14, x2, y2, y8), length of tertiary septa (y13), outer length of wall dissepiment (x4, x15), or thickness of costosepta (x18, x5, x9, x10). 
Comparison with species in Panamá (Analysis 2)

The results of canonical discriminant analysis comparing the Belize growth forms with genetically distinguished species in Panamá indicated that the 3 growth forms from Belize differed to varying degrees from their counterparts in Panamá (Fig. 4). Most importantly, the columns from Belize had significantly lower values along the first canonical variate (Mann-
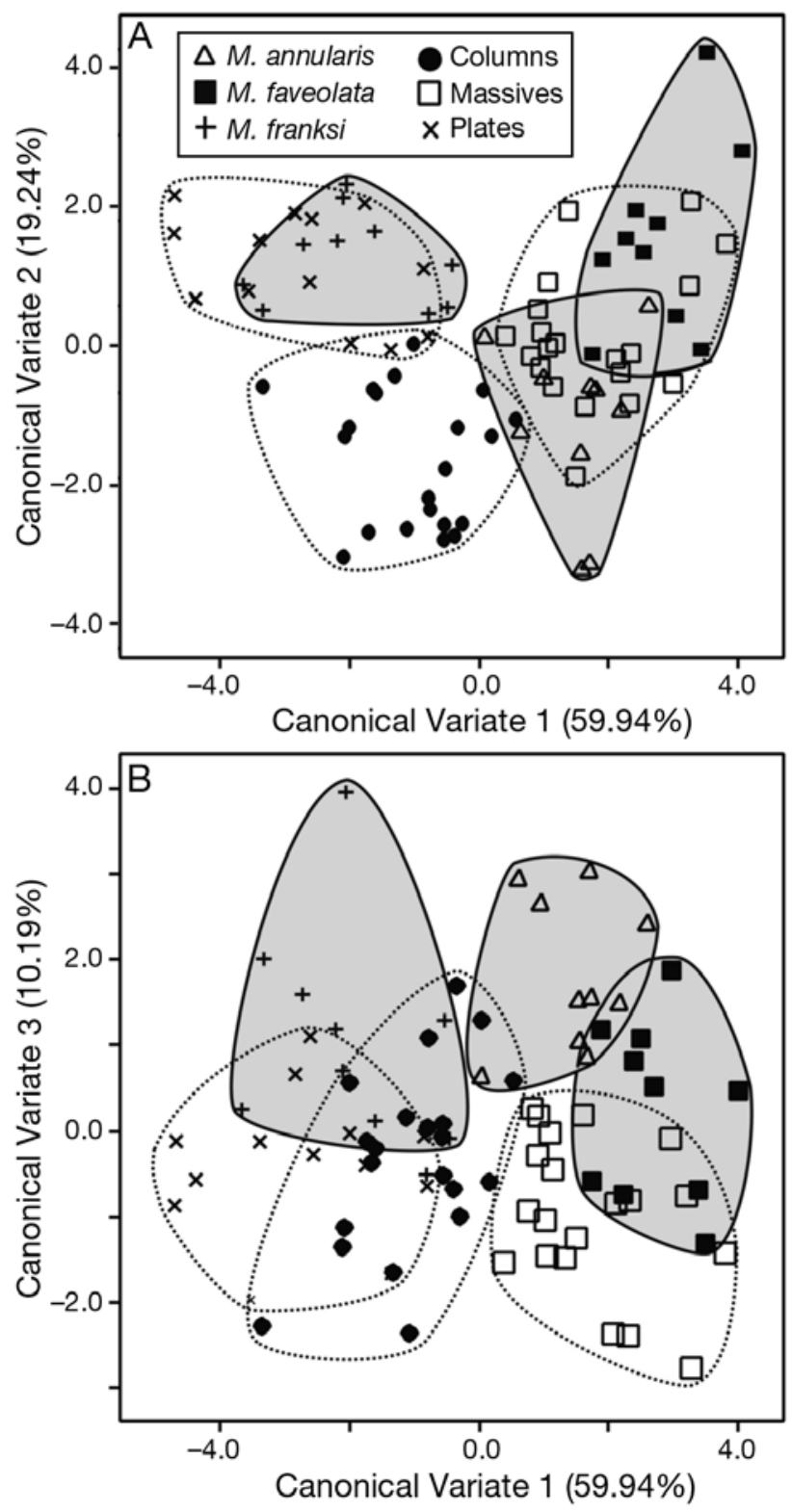

Fig. 4. Plots of scores on canonical variates comparing the 3 growth forms in Belize with the 3 species in Panamá (Analysis 2 ). Each point on the plots represents 1 colony; dotted polygons enclose the Belize growth forms and solid polygons (shaded) enclose the Panamá species. (A) Canonical Variate 1 vs. Canonical Variate 2. (B) Canonical Variate 1 vs. Canonical Variate 3
Whitney $\left.U_{1} \mathrm{p}<<0.001\right)$ than the columns from Panamá (= Montastraea annularis s.s.) (Fig. 4). However, the massive and platy growth forms in Belize appeared to be more similar to their Panamánian counterparts ( $M$. faveolata and $M$. franksi respectively), with differences being significant for massives (Mann-Whitney $U, \mathrm{p}=0.006$ ) but not for plates (Mann-Whitney $U, p=0.208$ ). The first canonical variate was strongly correlated with corallite wall thickness (y4, y15, y9, y10), which was significantly thicker in the columns from Belize than in the columns from Panamá (Table 1).

Scores on the second canonical variate (Fig. 4), which was correlated with corallite size (csize, y1, y19, y7) and dissepiment length (x6, x17), indicated possible differences between massives in Belize and Panamá (Mann-Whitney $U, \mathrm{p}=0.005$ ), but not between columns (Mann-Whitney $U, p=0.268$ ) or between plates (Mann-Whitney $U, \mathrm{p}=0.832$ ). However, these differences were not confirmed by Tukey's HSD tests performed on the original variables (Table 1). Likewise, scores on the third canonical variate, which was correlated with the length and thickness of the tertiary septa (y13, x10, x15) and the extension of the primary costae (x14), indicated possible differences between all 3 growth forms in Belize and Panamá (Fig. 4) (for columns: Mann-Whitney $U, \mathrm{p} \ll 0.001$; for massives: Mann-Whitney $U$, $\mathrm{p}=0.003$; for plates: Mann-Whitney $U, \mathrm{p}=0.002$ ). These differences were confirmed only between plates in Tukey's HSD tests performed on the original variables (Table 1).

The genetically distinct species from Panamá differed significantly from one another on Canonical Variates 1 (for Montastraea annularis s.s. vs. $M$. franksi, $M$. faveolata vs. M. franksi, and $M$. annularis s.s. vs. $M$. faveolata, Mann-Whitney $U, \mathrm{p} \ll 0.001$ ) and 2 (for both $M$. annularis s.s. vs. $M$. franksi and $M$. annularis s.s. vs. M. faveolata, Mann-Whitney $U, \mathrm{p} \ll 0.001$; but not for $M$. faveolata vs. $M$. franksi, Mann-Whitney $U, \mathrm{p}=0.853$ ) (Fig. 4). The differences were less pronounced on Canonical Variate 3 (for $M$. annularis s.s. vs. $M$. faveolata, Mann-Whitney $U, \mathrm{p}=0.004$; for $M$. annularis s.s. vs. $M$. franksi, Mann-Whitney $U, \mathrm{p}=$ 0.123; for $M$. faveolata vs. $M$. franksi, Mann-Whitney $U, \mathrm{p}=0.165)$. These results indicated that Canonical Variates 1 and 2 were more effective at distinguishing species than Canonical Variate 3. Canonical Variate 3 distinguished the 3 Belize growth forms collectively as a group from a group formed by the 3 Panamá species; however, the 2 collective groups overlap to a greater degree than the overlap observed between species within each group (Fig. 4B).

As in the Belize growth forms, multiple comparisons tests performed on each of the original variables 
(Table 1) revealed that wall thickness (y4, y15, y9, y10) was thin in massives (Montastraea faveolata), and thick in plates ( $M$. franksi). However, unlike Belize, columns ( $M$. annularis s.s) from Panamá had thin walls that are similar to massives. Like Belize, Panamá massives (M. faveolata) had larger corallite diameters (y1) and centroid sizes (csize), longer primary and secondary septa (y19, y7), and more extensive inner wall dissepiments $(\mathrm{x} 6, \mathrm{x} 17)$ than the other 2 species.

Environmental variation within Belize growth forms (Analyses 3 to 5)

The results of canonical discriminant analysis comparing colonies from different environments within each of the 3 Belize growth forms showed that colonies from different environments are distinct and separated by gaps within all 3 growth forms (Fig. 3B-D). In columns and massives, corallite size (csize, y19) was correlated with the first canonical variate (Table A3, Analyses 3 and 4), and decreased with water depth in both growth forms. In plates, although low in value, wall thickness (y10) and tertiary costoseptum thickness (x9) had the highest correlations with the first canonical variate (Table A3, Analyses 3 and 4), and increased with water depth.

Comparisons between canonical variates (Table A3) in analyses distinguishing growth forms (Analysis 1) and environments within growth forms (Analyses 3 to 5) indicated that different variables are involved in variation within and among species. Wall thickness (especially y4, y15, y9, y10) and development of wall dissepiment (x6, x17) play a more important role in distinguishing species, whereas primary septum length (y19) and costa extension (y14) are more important in distinguishing environments within columns and massives. Within plates, however, wall thickness does distinguish environments, but unlike analyses distinguishing growth forms (or species), it varies in combination with the shape of the tertiary costoseptum (x9, $\mathrm{x} 10, \mathrm{x} 4, \mathrm{x} 15)$, so its pattern of variation still differs from that observed between species.

Comparison of environmental variation within species with species differences (Analyses 6 and 7)

The results of canonical discriminant analyses comparing the Panamá species with environmental variation in transplanted Montastraea faveolata from Jamaica (Fig. 5A, Analysis 6) showed that the Panamá species are distinct and differ primarily on the first canonical variate, which was strongly correlated with wall thickness (y4, y15, y9, y10, y3, y16) (Table A3). In contrast, colonies from the Jamaica environments overlap and differed mainly along Canonical Variate 2, which was correlated with dissepiment length (x6, x17) (Table A3). M. annularis s.s. from Panamá was further distinguished on Canonical Variate 3 (not shown), which was correlated with a combination of corallite size (csize, y1, y19, y7) and dissepiment length (x6, x17) (Table A3). Differences among environments only accounted for a portion of the range of variation along Canonical Variate 1 (which distinguished the 3 species), but none of the variation along Function 3 (which distinguished $M$. annularis s.s.). Differences among species accounted for little, if any, of the variation along Canonical Variate 2 (which distinguished environments).

Comparisons between canonical variates (Table A3) in analyses distinguishing growth forms (Analysis 1), species (Analysis 2, 6), environments within growth forms (Analyses 3 to 5), and environments within species (Analysis 6) indicated that different variables are involved in corallite morphological variation within and among species. Canonical Variate 1 in Analysis 6 was similar to Canonical Variate 1 in comparisons among growth forms (Analysis 1) and species (Analysis 2). Canonical variate 3 in Analysis 6 was similar to Canonical Variate 2 in comparisons among growth forms (Analysis 1) and species (Analysis 2). Canonical Variate 2 in Analysis 6 was most similar to the second canonical variate in comparisons among environments within the massive growth form (Analysis 4).

Canonical discriminant analyses comparing samples taken below the alizarin line with samples of the same colonies taken above the alizarin line (Fig. 5B,C, Analysis 7) showed that colonies transplanted between the 3 Jamaican environments are capable of changing their morphology in response to transplantation. The variation observed among Jamaican populations can therefore be interpreted as caused by ecophenotypic plasticity.

\section{Ecological distribution}

Species of the Montastraea 'annularis' complex showed varying distributions with depth (Fig. 6). At all 3 sites studied, $M$. faveolata was the most abundant member in the shallowest reef habitats (2 to $5 \mathrm{~m}$ ), with $M$. annularis s.s. the most abundant at intermediate depths (10 to $15 \mathrm{~m}$ ) and $M$. franksi in deeper depths (20 to $30 \mathrm{~m}$ ) (Fig. 6). The only exception to this pattern was the dominance of $M$. faveolata over $M$. annularis in $10 \mathrm{~m}$ water depth at Carrie Bow Cay. ANOSIM using the entire data set showed that the composition of the assemblages was significantly different over 

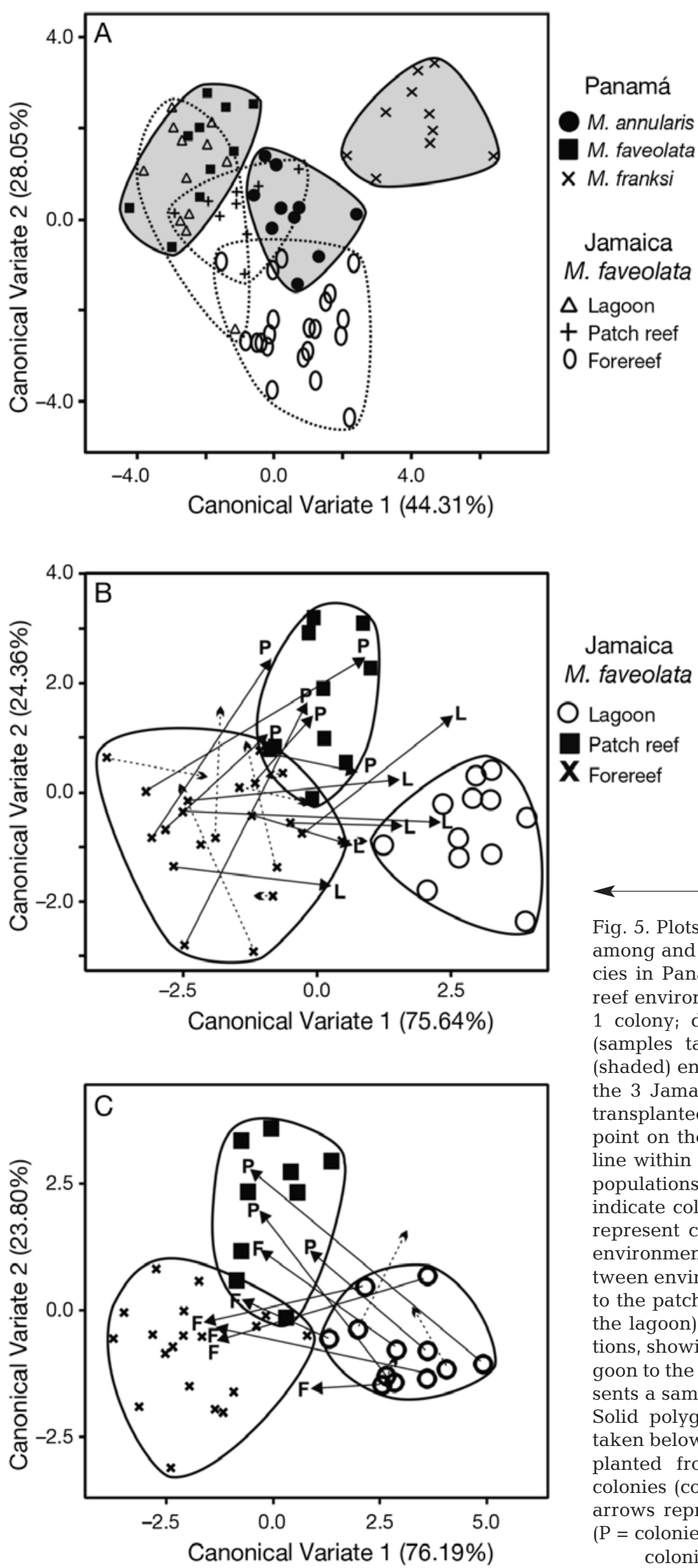

sites and depths (Table 2). Applying the Bonferroni correction gives $\alpha=0.016$ for the pairwise comparisons of sites, so Tobacco Reef communities were significantly different from those at Curlew Cay (Table 2, Fig. 7), showing greater abundance of $M$. annularis and lower abundance of $M$. faveolata at the Tobacco Reef site. Applying the Bonferroni correction gives $\alpha=0.003$ for the pairwise comparisons of depths, so all depths were significantly different from one another except the $2 \mathrm{~m}$ lagoonal assemblages, which were not significantly different from the $5 \mathrm{~m}$ reef front assemblages (Table 2). Results from PERMANOVA excluded the $2 \mathrm{~m}$ lagoon depth. As with ANOSIM, there was an overall site $\left(F_{2,74}=\right.$ 5.16, $\mathrm{p}=0.006)$ and depth $\left(F_{4,74}=88.71, \mathrm{p}<\right.$ $0.001)$ effect, plus a significant interaction term $\left(F_{8,74}=2.66, \mathrm{p}=0.010\right)$. Also similar to ANOSIM results, all PERMANOVA pairwise comparisons for depth $(5,10,15,20$, and $30 \mathrm{~m}$ ) were significant using a Bonferroni-corrected $\alpha=0.005$. The site $\times$ depth interaction showed significant pairwise site comparisons at the depths of 15, 20, and 30 m, for Tobacco Reef versus Curlew Cay, and at $15 \mathrm{~m}$ for Tobacco Reef versus Carrie Bow Cay (Table 3), using a Bonferronicorrected $\alpha=0.017$.

Fig. 5. Plots of scores on canonical variates comparing variation among and within species. (A) Analysis 6, comparing the 3 species in Panamá with colonies of Montastraea faveolata from 3 reef environments in Jamaica. Each point on the plot represents 1 colony; dotted polygons enclose the Jamaican populations (samples taken below the alizarin line) and solid polygons (shaded) enclose the Panamá species. (B) Comparisons between the 3 Jamaican populations, showing changes within colonies transplanted from the forereef to the patch reef and lagoon. Each point on the plot represents a sample taken below the alizarin line within each colony. Solid polygons enclose the 3 Jamaican populations (samples taken below the alizarin line) and arrows indicate colonies transplanted from the forereef. Dotted arrows represent control colonies (colonies moved within the forereef environment); solid arrows represent colonies transplanted between environments $(\mathrm{P}=$ colonies transplanted from the forereef to the patch reef; $\mathrm{L}=$ colonies transplanted from the forereef to the lagoon). (C) Comparisons between the 3 Jamaican populations, showing changes within colonies transplanted from the lagoon to the patch reef and forereef. Each point on the plot represents a sample taken below the alizarin line within each colony. Solid polygons enclose the 3 Jamaican populations (samples taken below the alizarin line) and arrows indicate colonies transplanted from the lagoon. Dotted arrows represent control colonies (colonies moved within the lagoon environment); solid arrows represent colonies transplanted between environments $(\mathrm{P}=$ colonies transplanted from the lagoon to the patch reef; $\mathrm{F}=$ colonies transplanted from the lagoon to the forereef) 

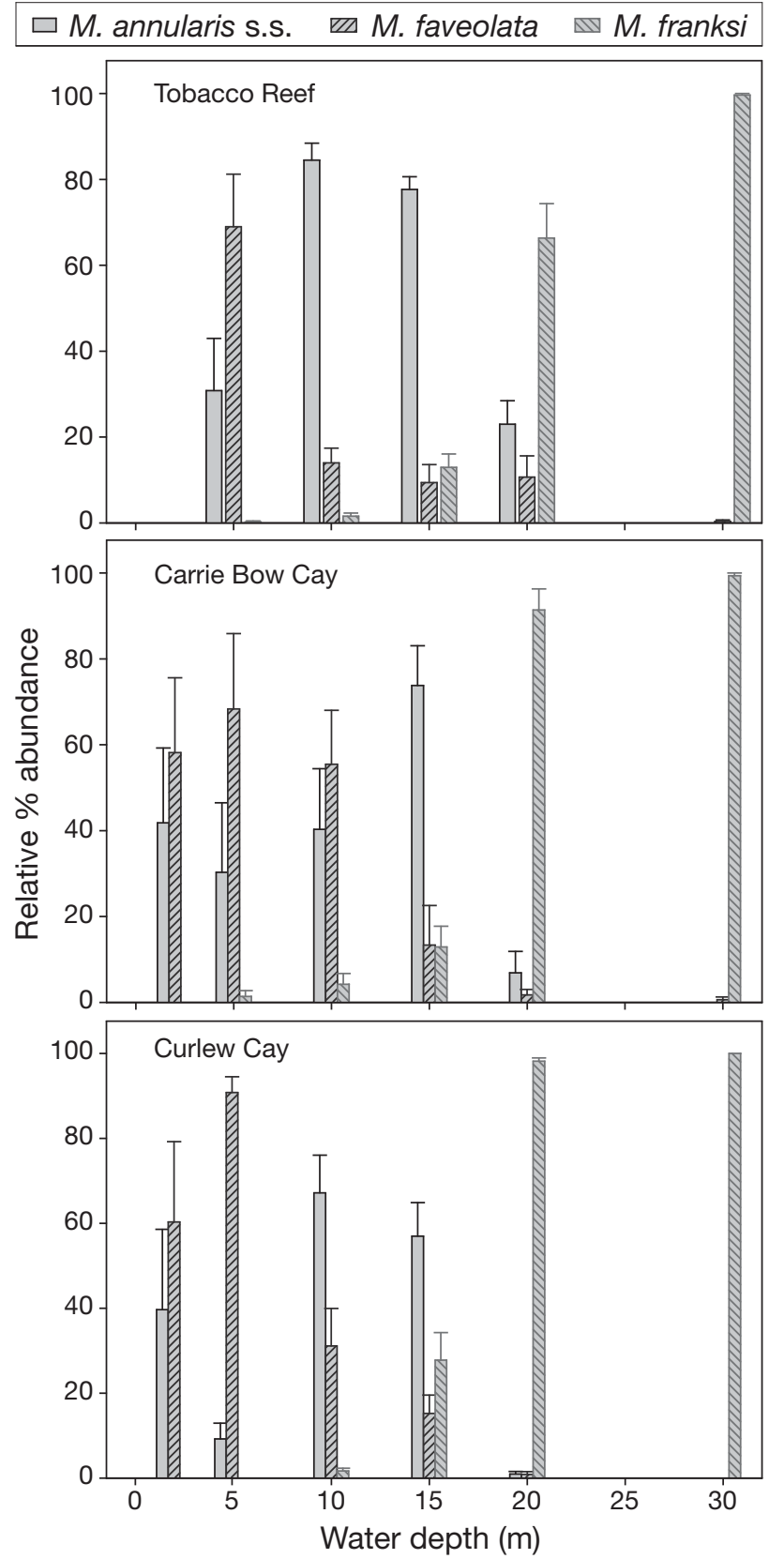

Fig. 6. Ecological distribution of the 3 species of the Montastraea 'annularis' species complex from each of the 3 sites in Belize: (A) Tobacco Reef; (B) Carrie Bow Cay; and (C) Curlew Cay. At all 3 sites, M. faveolata was most abundant in both shallow water lagoon and reef crest environments; $M$. annularis s.s. was most abundant in shallow to intermediate water depths, and $M$. franksi was most abundant in the deeper water depths. Error bars = SEM

Ordination of the Montastraea assemblages agreed well with the ANOSIM results with lagoonal $2 \mathrm{~m}$ assemblages indistinguishable from the reef front $5 \mathrm{~m}$ assemblages (Fig. 8). A clear depth gradient in community composition occurred along Dimension 1 of the
Table 2. Results of 2-way crossed analysis of similarities (ANOSIM) for site and depth among living assemblages of the Montastraea 'annularis' species complex from reefs near Carrie Bow Cay (CBC), Belize. Depths at $2 \mathrm{~m}$ are from the lagoon; all others are from the windward reef front. $\mathrm{R}=$ ANOSIM test statistic $;$ Tob $=$ Tobacco Reef; Curlew $=$ Curlew Cay

\begin{tabular}{|lcc|}
\hline Main effect & $\mathrm{R}$ & $\mathrm{p}$ \\
\hline Site & & \\
Overall & 0.202 & 0.0001 \\
CBC vs. Tob & 0.270 & 0.0002 \\
CBC vs. Curlew & -0.060 & 0.888 \\
Curlew vs. Tob & 0.450 & 0.0001 \\
Depth & & \\
Overall & 0.734 & $<0.0001$ \\
15 vs. $10 \mathrm{~m}$ & 0.445 & $<0.0001$ \\
15 vs. $20 \mathrm{~m}$ & 0.747 & $<0.0001$ \\
15 vs. $5 \mathrm{~m}$ & 0.769 & $<0.0001$ \\
15 vs. $30 \mathrm{~m}$ & 1.0 & $<0.0001$ \\
15 vs. $2 \mathrm{~m}$ & 0.792 & 0.0002 \\
10 vs. $20 \mathrm{~m}$ & 0.867 & $<0.0001$ \\
10 vs. $5 \mathrm{~m}$ & 0.479 & $<0.0001$ \\
10 vs. $30 \mathrm{~m}$ & 1.0 & $<0.0001$ \\
10 vs. $2 \mathrm{~m}$ & 0.534 & $<0.0001$ \\
20 vs. $5 \mathrm{~m}$ & 0.876 & $<0.0001$ \\
20 vs. $30 \mathrm{~m}$ & 0.449 & 0.0003 \\
20 vs. $2 \mathrm{~m}$ & 0.976 & $<0.0001$ \\
5 vs. $30 \mathrm{~m}$ & 0.988 & 0.0001 \\
5 vs. $2 \mathrm{~m}$ & 0.16 & $<0.0001$ \\
30 vs. $2 \mathrm{~m}$ & 1.0 & \\
\hline
\end{tabular}

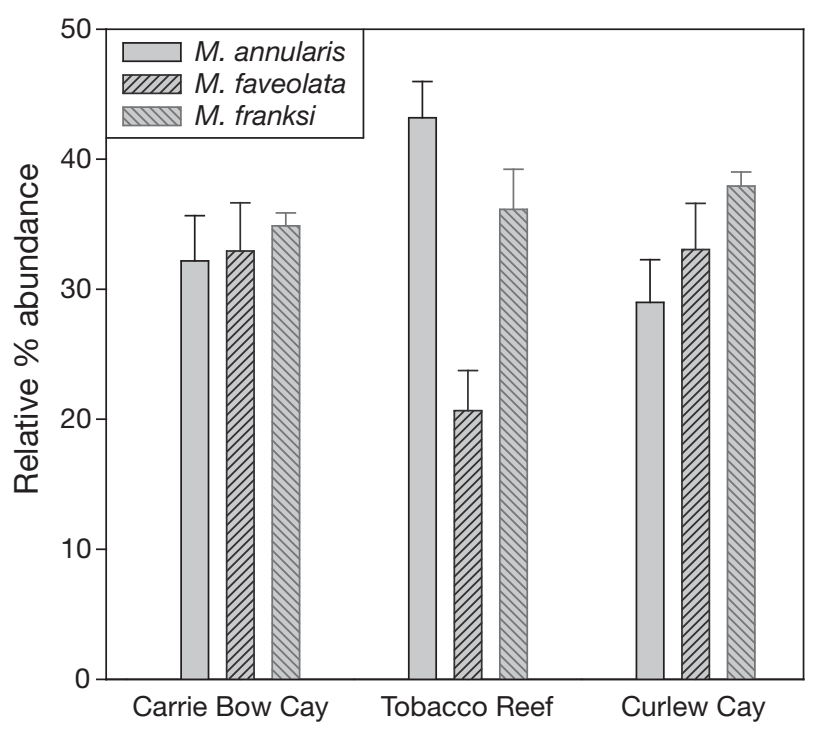

Fig. 7. Distribution of the 3 species of the Montastraea 'annularis' species complex among the 3 sites in Belize. Tobacco Reef had a much higher abundance of $M$. annularis and a much lower abundance of $M$. faveolata than the other 2 sites, which showed broadly similar distributions among species. Error bars $=$ SEM

ordination, with variance along Dimension 2 decreasing with water depth (Fig. 8). 
Table 3. Results of pairwise a posteriori comparisons for site differences derived from the 2-way crossed PERMANOVA (site $\times$ depth) among living assemblages of the Montastraea 'annularis' species complex from reefs near Carrie Bow Cay $(\mathrm{CBC})$, Belize. All depths are from the windward reef front. Tob = Tobacco Reef; Curlew = Curlew Cay

\begin{tabular}{|lcc|}
\hline Groups & $t$ & $\mathrm{p}$ \\
\hline $\mathbf{5}$ m water depth & & \\
CBC vs. Tob & 1.130 & 0.399 \\
CBC vs. Curlew & 1.303 & 0.323 \\
Tob vs. Curlew & 0.943 & 0.409 \\
10 m water depth & & \\
CBC vs. Tob & 1.710 & 0.043 \\
CBC vs. Curlew & 1.563 & 0.113 \\
Tob vs. Curlew & 1.500 & 0.121 \\
15 m water depth & & \\
CBC vs. Tob & 2.153 & 0.009 \\
CBC vs. Curlew & 1.274 & 0.198 \\
Tob vs. Curlew & 3.506 & 0.007 \\
20 m water depth & & \\
CBC vs. Tob & 2.324 & 0.019 \\
CBC vs. Curlew & 0.732 & 0.543 \\
Tob vs. Curlew & 3.900 & 0.008 \\
30 m water depth & & \\
CBC vs. Tob & 2.171 & 0.037 \\
CBC vs. Curlew & 1.019 & 0.388 \\
Tob vs. Curlew & 2.545 & 0.008 \\
& & \\
& &
\end{tabular}

\section{DISCUSSION}

\section{Species boundaries in the Montastraea 'annularis' complex in Belize}

A great deal of information, absent when Graus \& Macintyre $(1976,1982)$ undertook their studies of 'phenotypic plasticity' in the early 1970s, has now been assembled that argues for the existence of 3 species in the Montastraea 'annularis' complex. The nature of the evidence is such that no single line of inquiry can unequivocally differentiate all 3 species in all cases. However, when several different kinds of information are taken together, a convincing case can be made for species differences. Earlier genetic work (Knowlton et al. 1992) has been supplanted by more recent work (Fukami et al. 2004), but ambiguities remain. For example, even though clear differences in corallite wall measurements exist between species when colony tops are treated alone, there is still overlap between the colony edges of $M$. annularis s.s. and $M$. franksi (Knowlton \& Budd 2001). The major lines of evidence are genetic, reproductive isolation, morphological, and ecological.

Morphometric analysis of corallite architecture confirms that the 3 growth forms in Belize represent separate species. Although the 3 growth forms overlap slightly at their margins (i.e. they are not separated

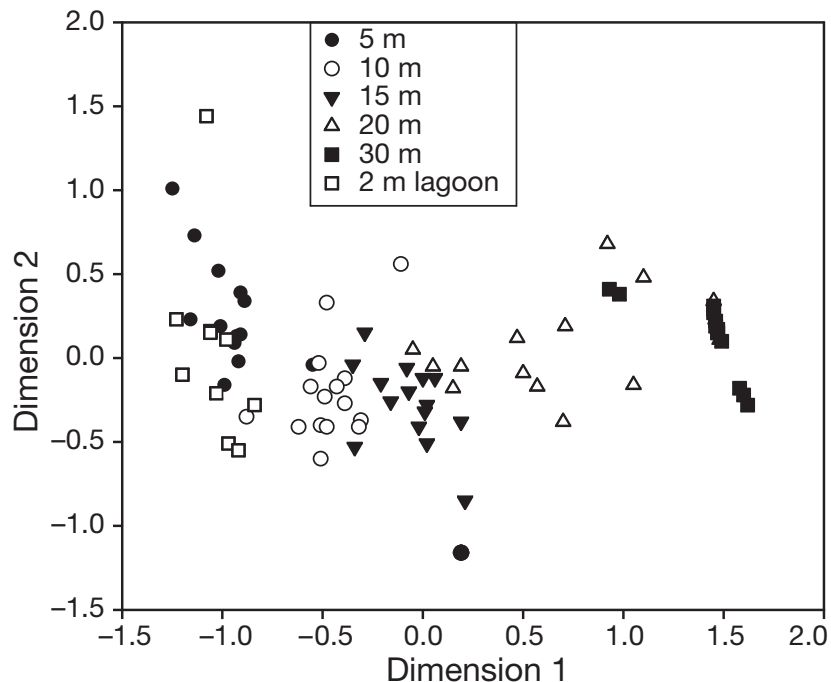

Fig. 8. Nonmetric multidimensional scaling ordination results for entire set of 85 transects of abundance of Montastraea 'annularis' species complex from 3 reefs surrounding Carrie Bow Cay in Belize. Assemblages from lagoonal (2 m) habitats were most aligned with those from shallow water reef crest habitats $(5 \mathrm{~m})$ with the remainder of the assemblages distributed across a depth gradient. Note the decrease in variance of the Montastraea assemblages from shallow to deep water $(2$-dimensional analysis, stress $=0.08)$

from one another by gaps on canonical variate plots), they are nevertheless distinct (Fig. 3A). No overlap has been detected between species in the San Blas Islands of Panamá, where the 3 species are separated by gaps (Budd \& Klaus 2001, Knowlton \& Budd 2001); however, unlike the present study which sampled exposed reef environments at a range of water depths, specimens in analyses of the San Blas Islands were all collected from a protected reef environment at depths of $\sim 10 \mathrm{~m}$. The greater environmental variability in the present study may have been responsible for the greater morphological variability within each growth form (as illustrated in our Fig. 3B-D, but see Klaus et al. 2007), and hence the slight overlap observed in the present study. Indeed, slight overlap has been observed in Panamá, when specimens from the San Blas Islands and Bocas del Toro are both included in the same analysis (Fukami et al. 2004). Clearly the slight overlap in the present study is minor by comparison with the complete overlap observed in the Bahamas, which has been interpreted as having been caused by hybridization, most likely in the geological past (Budd \& Pandolfi 2004, Fukami et al. 2004). Thus, on a broader latitudinal scale, the clear-cut species boundaries in the southern and western Caribbean appear to fade in northern latitudes (Bahamas and Florida), and only $M$. franksi is reported from the northern-most geographical distribution of the genus, in Bermuda (Logan 1988, Weil \& Knowlton 1994). 
Morphometric analyses of corallite architecture (Fig. 4) also show that the massives in Belize are similar to Montastraea faveolata in Panamá (San Blas Islands), and that the plates in Belize are similar to $M$. franksi in Panamá (San Blas Islands). However, the columns in Belize differ from $M$. annularis s.s. in Panamá (San Blas Islands). As would be expected, differences of a similar magnitude are also detected between columns in the Bahamas and from $M$. annularis s.s. in Panamá due to hybridization in the Bahamas (Budd \& Pandolfi 2004, Fukami et al. 2004), but they also occur where hybridization has not been inferred, for example, within Panamá itself between Bocas del Toro and the San Blas Islands (Fukami et al. 2004), between Curaçao and Panamá (San Blas Islands) (Klaus et al. 2007), and between the Pleistocene of Barbados and Panamá (San Blas Islands) (Pandolfi et al. 2002). Relevant here is the fact that all 3 species from the Florida Keys are capable of hybridizing successfully under laboratory conditions (Szmant et al. 1997), which suggests that some hybridization occurs in nature and therefore, hybrid colonies are bound to be found in reefs. But our morphological results do not indicate much hybridization in Belize, and further investigation is needed to understand the degree to which these 3 species are genetically distinct here. One possibility is that hybrids occur but the juveniles either have low survivorship or are sterile.

Although some geographical differences are observed within all 3 species (Fig. 4B), geographical variation within Montastraea annularis s.s. is more pronounced than in the other 2 species. The morphological characters that differ between species are the same as those that differ between the columns in Belize and $M$. annularis s.s. in Panamá (San Blas Islands) (Fig. 4), indicating a possible genetic component to the differences between the columns in Belize and M. annularis s.s. in Panamá (San Blas Islands). However, as noted in 'Materials and methods', environmental differences also exist between sampling sites in Belize and Panamá (San Blas Islands) so environmental variation cannot be entirely ruled out. In general, the observed spatial variation resembles the temporal variation within columnar $M$. annularis s.s. caused by character release following the extinction of organ-pipe M. nancyi (Pandolfi et al. 2002, Pandolfi 2007).

As illustrated by Fig. 5, different aspects of corallite morphology vary within and between species. Distinctions among species involve wall thickness ( $44, \mathrm{y} 15$, y9, y10, y3, y16), whereas distinctions among environments within species involve corallite size (csize, y1, y19, y7) within both columns and massives, and wall structure (the shape of the tertiary costoseptum; $x$, $\mathrm{x} 10, \mathrm{x} 4, \mathrm{x} 15)$ within plates. Wall dissepiment (x6, x17) also varies within massives (as seen in the Jamaican transplants). However, the trajectories of variation within (dotted polygons) and between (solid polygons) species on Fig. 5 are not completely perpendicular, suggesting a limited degree of correlation between the 2 aspects of variation. Such correlation would be expected if natural selection and adaptation were at work during speciation.

\section{Ecological distribution in Belize}

Our study of the ecological distribution of the 3 species of the Montastraea 'annularis' complex shows that they strongly correlate with depth, probably reflecting differing responses to light and wave energy. The results mimic those found by Graus \& Macintyre (1976), with massive and columnar forms more abundant in shallower water and plate forms more abundant in deeper water as light attenuates with depth. The consistency of these patterns among sites lends credence to their general applicability, at least for reefs of Belize (Fig. 6). The distribution of species of the $M$. 'annularis' complex has been studied previously in Panamá (Weil \& Knowlton 1994) and Curaçao (van Veghel 1994) and similar patterns of columns and massives (shallow) versus plate corals (deep) has been found. Although the 3 coral species correlate directly with depth, and presumably light penetration, all 3 species also occupy a large depth range, with larger variance and overlap in species abundances in shallow than deep water. Thus, their fundamental niche is larger than their favored realized niche. This suggests that future work on the distribution of these species may profitably be geared toward understanding the role of niche differentiation, which has been previously proposed to operate in the maintenance of diversity in the $M$. 'annularis' complex (Knowlton \& Jackson 1994, Pandolfi et al. 2002).

The ANOSIM and PERMANOVA analyses of abundance singled out Tobacco Reef for site differences and showed that the lagoonal $2 \mathrm{~m}$ assemblages were similar only to reef front assemblages at $5 \mathrm{~m}$ depth (Table 2). The site $\times$ depth interaction from the PERMANOVA confirmed differences between Tobacco Reef and Curlew Cay at depths between 15 and 30 m (Table 3), possibly reflecting varying histories of disturbance or subtle geomorphological variation between these 2 reefs, with Tobacco Reef having a leeward low island (South Water Cay) and Curlew Cay having a leeward, totally submerged lagoon. Regardless of these subtle differences in species abundance at the sites and depths, the patterns in relative abundance among the 3 species of the Montastraea 'annularis' complex were remarkably similar among sites and varied predictably among depths (Fig. 6) 
As part of a broad research program to understand the evolution and ecology of the complex over significant intervals of geological time, paleoecological data on the abundance and distribution of these growth forms has been gathered from a number of Pleistocene reefs of the Caribbean. Massive, columnar, and sheet (plate) members of the modern Montastraea 'annularis' species complex and 1 new species that does not live today, $M$. nancyi, which has an organ-pipe growth form (Pandolfi 2007), are a common feature of Caribbean shallow water Pleistocene deposits (Pandolfi \& Jackson 1997, 2006, Pandolfi 1999, Pandolfi et al. 1999, 2002, Klaus \& Budd 2003). Thus, the maintenance of diversity within the $M$. 'annularis' species complex has existed at least since the Pleistocene on Caribbean coral reefs, even extending back 600000 yr on Barbados (Mesolella 1967, Jackson 1992).

Our previous studies on the ecological zonation of the different growth forms through time on Barbados have also shown correlations with depth; massive, columnar, and organ-pipe species were more common in shallow water, whereas plate forms favored deeper water (Pandolfi et al. 2001, 2002). The similar results from the present study of modern specimens of Belize lend credibility to the antiquity of these different growth forms as separate species during the Pleistocene, each favoring separate reef zones. Our study, and indeed the entire history of study of the Montastraea 'annularis' species complex, supports the notion of caution against underestimation of biological diversity on coral reefs in particular, and marine ecosystems in general (Knowlton 2001).

Acknowledegments. I. Macintyre supplied 11 colonies for morphometric analysis from Carrie Bow Cay reef. S. Benson, C. Decourley, J. Han, A. Jabo, D. Miller, and M. Parrish provided diving assistance. A. L. Perez, H. Schultz, and T. Fadiga made measurements on coral thin sections. This research was funded by NSF grants EAR97-25273 and DEB-0343208 to A.F.B., and by the Smithsonian Institution's Caribbean Coral Reef Ecosystems program (CCRE), the University of Queensland Travel Grants to A.F.B. and J.M.P., and the Australian Research Council Centre of Excellence in Coral Reef Studies (www.coralcoe.org.au/) to J.M.P. This is the Smithsonian Institution's Caribbean Coral Reef Ecosystems (CCRE) contribution number 828, supported in part by the Hunterdon Oceanographic Research Fund.

\section{LITERATURE CITED}

Anderson MJ (2001) A new method for non-parametric multivariate analysis of variance. Austral Ecol 26:32-46

Anderson MJ (2005) PERMANOVA: a FORTRAN computer program for permutational multivariate analysis of variance. Department of Statistics, University of Auckland, Auckland

Bookstein FL (1991) Morphometric tools for landmark data. Cambridge University Press, Cambridge
Bray JR, Curtis JT (1957) An ordination of the upland forest communities of southern Wisconsin. Ecol Monogr 27: $325-349$

Budd AF (1993) Variation within and among morphospecies of Montastraea. Cour Forschinst Senckenb 164:241-254

Budd AF, Johnson KG (1996) Recognizing species of Late Cenozoic Scleractinia and their evolutionary patterns. Paleontol Soc Pap 1:59-79

Budd AF, Klaus JS (2001) The origin and early evolution of the Montastraea 'annularis' species complex (Anthozoa: Scleractinia). J Paleontol 75:527-545

Budd AF, Pandolfi JM (2004) Overlapping species boundaries and hybridization within the Montastraea 'annularis' reef coral complex in the Pleistocene of the Bahama Islands. Paleobiology 30:396-425

> Clarke KR (1993) Non-parametric multivariate analyses of changes in community structure. Aust J Ecol 18:117-143

Clarke KR, Warwick RM (2001) Change in marine communities: an approach to statistical analysis and interpretation, 2nd edn. PRIMER-E, Plymouth

Connell JH (1978) Diversity in tropical rainforests and coral reefs. Science 199:1302-1310

Ellis J, Solander D (1786) The natural history of many curious and common zoophytes. White \& Son, London

Field JG, Clarke KR, Warwick DRM (1982) A practical strategy for analyzing multispecies distribution patterns. Mar Ecol Prog Ser 8:37-52

Foster AB (1979) Phenotypic plasticity in the reef corals Montastraea annularis (Ellis and Solander) and Siderastrea siderea (Ellis and Solander). J Exp Mar Biol Ecol 39:25-54

Fukami H, Budd AF, Levitan DR, Jara J, Kersanach R, Knowlton N (2004) Geographic differences in species boundaries among members of the Montastraea annularis complex based on molecular and morphological markers. Evolution 58:324-337

$>$ Goreau TF (1959) The ecology of Jamaican coral reefs. I. Species composition and zonation. Ecology 40:67-90

Goreau TF, Wells JW (1967) The shallow-water Scleractinia of Jamaica: revised list of species and their vertical distribution range. Bull Mar Sci 17:442-453

> Graus RR, Macintyre IG (1976) Control of growth form in colonial corals: computer simulation. Science 193:895-897

Graus RR, Macintyre IG (1982) Variations in the growth forms of the reef coral Montastraea annularis (Ellis and Solander): a quantitative evaluation of growth response to light distribution using computer simulation. In: Rützler $\mathrm{K}$, Macintyre IG (eds) The Atlantic barrier reef ecosystem at Carrie Bow Cay, Belize. 1. Structure and communities. Smithson Contrib Mar Sci 12:441-464

Gregory JW (1895) Contributions to the paleontology and physical geology of the West Indies. Q J Geol Soc Lond 51:255-312

> Holcomb M, Pandolfi JM, Macintyre IG, Budd AF (2004) Use of X-radiographs to distinguish members of the Montastraea 'annularis' reef coral species complex. Hydrobiologia 530-531:211-222

Jackson JBC (1992) Pleistocene perspectives on coral reef community structure. Am Zool 32:719-731

Jackson JBC, Budd AF, Pandolfi JM (1996) The shifting balance of natural communities? In: Jablonski D, Erwin DH, Lipps JH (eds) Evolutionary paleobiology: essays in honor of James W. Valentine. University of Chicago Press, Chicago, IL, p 89-122

- Klaus JS, Budd AF (2003) Comparison of Caribbean coral reef communities before and after Plio-Pleistocene faunal turnover: analyses of two Dominican Republic reef sequences. Palaios 18:3-21 
Klaus JS, Budd AF, Heikoop JM, Fouke BW (2007) Environmental controls on corallite morphology in the reef coral Montastraea annularis. Bull Mar Sci 80:233-260

Knowlton N (2001) Who are the players on coral reefs and does it matter? The importance of coral taxonomy for coral reef management. Bull Mar Sci 69:10-13

Knowlton N, Budd AF (2001) Recognizing coral species past and present. In: Jackson JBC, McKinney FK, Lidgard S (eds) Process from pattern in the fossil record: essays in honor of Alan Cheetham. University of Chicago Press, Chicago, IL, p 97-119

Knowlton N, Jackson JBC (1994) New taxonomy and niche partitioning on coral reefs: jack of all trades or master of some? Trends Ecol Evol 9:7-9

Knowlton N, Weil E, Weigt LA, Guzmán HM (1992) Sibling species in Montastraea annularis, coral bleaching, and the coral climate record. Science 255:330-333

Knowlton N, Maté JL, Guzmán HM, Rowan R, Jara J (1997) Direct evidence for reproductive isolation among the three species of the Montastraea annularis complex in Central America (Panamá, Honduras). Mar Biol 127: 705-711

Kruskal JB (1964) Multidimensional scaling by optimizing goodness of fit to a nonmetric hypothesis. Psychometrika 29:1-27

Levitan DR, Fukami H, Jara J, Kline D and others (2004) Mechanisms of reproductive isolation among sympatric broadcast-spawning corals of the Montastraea annularis species complex. Evolution 58:308-323

Logan A (1988) Holocene reefs of Bermuda. Sedimenta 11. The University of Miami, Miami Beach, FL

Lopez JV, Knowlton N (1997) Discrimination of sibling species in the Montastraea annularis complex using multiple genetic loci. Proc 8th Int Coral Reef Symp, Panamá 2: $1613-1618$

Lopez JV, Kersanach R, Rehner SA, Knowlton N (1999) Molecular determination of species boundaries in corals: genetic analysis of the Montastraea annularis complex using amplified fragment length polymorphisms and a microsatellite marker. Biol Bull 196:80-93

Manica A, Carter RW (2000) Morphological and fluorescence analysis of the Montastraea annularis species complex in Florida. Mar Biol 137:899-906

Mesolella KJ (1967) Zonation of uplifted Pleistocene coral reefs on Barbados, West Indies. Science 156:638-640

Minchin PR (1987) An evaluation of the relative robustness of techniques for ecological ordination. Plant Ecol 69: 89-107

Pandolfi JM (1996) Limited membership in Pleistocene reef coral assemblages from the Huon Peninsula, Papua New Guinea: constancy during global change. Paleobiology 22:152-176

Pandolfi JM (1999) Response of Pleistocene coral reefs to environmental change over long temporal scales. Am Zool 39:113-130

Pandolfi JM (2001) Numerical and taxonomic scale of analysis in paleoecological data sets: examples from Neo-tropical Pleistocene reef coral communities. J Paleontol 75: 546-563

Pandolfi JM (2007) A new, extinct Pleistocene reef coral from the Montastraea 'annularis' species complex. J Paleontol 81:472-482

Pandolfi JM, Jackson JBC (1997) The maintenance of diver-

Editorial responsibility: Charles Birkeland,

Honolulu, Hawaii, USA sity on coral reefs: examples from the fossil record: Proc 8th Int Coral Reef Symp, Panamá 1:397-404

Pandolfi JM, Jackson JBC (2001) Community structure of Pleistocene coral reefs of Curaçao, Netherlands Antilles. Ecol Monogr 71:49-67

Pandolfi JM, Jackson JBC (2006) Broad-scale patterns in Pleistocene coral reef communities from the Caribbean: implications for ecology and management. In: Aronson RB (ed) The destruction of coral reef ecosystems: paleoecological perspectives on the human role in a global crisis. Springer-Verlag, New York, p 201-236

Pandolfi JM, Minchin PR (1995) A comparison of taxonomic composition and diversity between reef coral life and death assemblages in Madang Lagoon, Papua New Guinea. Palaeogeogr Palaeoclimatol Palaeoecol 119: 321-341

Pandolfi JM, Llewellyn G, Jackson JBC (1999) Interpretation of ancient reef environments in paleoecological studies of community structure: Curaçao, Netherlands Antilles, Caribbean Sea. Coral Reefs 18:107-122

Pandolfi JM, Jackson JBC, Geister J (2001) Geologically sudden natural extinction of two widespread Late Pleistocene Caribbean reef corals. In: Jackson JBC, Lidgard S, McKinney FK (eds) Evolutionary patterns: growth, form and tempo in the fossil record. University of Chicago Press, Chicago, IL, p 120-158

Pandolfi JM, Lovelock CE, Budd AF (2002) Character release following extinction in a Caribbean reef coral species complex. Evolution 53:479-501

Shi GR (1993) Multivariate data analysis in palaeoecology and palaeobiogeography - a review. Palaeogeogr Palaeoclimatol Palaeoecol 105:199-234

Szmant AM, Weil E, Miller MW, Colón DE (1997) Hybridization within the species complex of the scleractinan Montastraea annularis. Mar Biol 129:561-572

Van Veghel MLJ (1994) Polymorphism in the Caribbean reef building coral Montastrea annularis. PhD thesis, University of Amsterdam

- Van Veghel MLJ, Bak RPM (1993) Interspecific variation of a dominant Caribbean reef building coral, Montastrea annularis: genetic, behavioral and morphometric aspects. Mar Ecol Prog Ser 92:255-265

Van Veghel MLJ, Bak RPM (1994) Reproductive characteristics of the polymorphic Caribbean reef building coral Montastrea annularis. III. Reproduction in damaged and regenerating colonies. Mar Ecol Prog Ser 109:229-233

Van Veghel MLJ, Cleary DFR, Bak RPM (1996) Interspecific interactions and competitive ability of the polymorphic reef-building coral Montastrea annularis. Bull Mar Sci 58: 792-803

Weil E, Knowlton N (1994) A multi-character analysis of the Caribbean coral Montastraea annularis (Ellis and Solander, 1786) and its two sibling species, M. faveolata (Ellis and Solander, 1786) and M. franksi (Gregory, 1895). Bull Mar Sci 55:151-175

Willis BL, van Oppen MJH, Miller DJ, Vollmer SV, Ayre DJ (2006) The role of hybridization in the evolution of reef corals. Annu Rev Ecol Evol Syst 37:489-517

Zelditch ML, Swiderski DL, Sheets HD, Finks WL (2004) Geometric morphometrics for biologists: a primer. Elsevier Academic Press, Amsterdam

Submitted: December 17, 2007; Accepted: May 13, 2008

Proofs received from author(s): September 20, 2008 